\title{
Canopy Position Affects Light Response Curves for Gas Exchange Characteristics of Apple Spur Leaves
}

\author{
Richard J. Campbell ${ }^{1}$, Richard P. Marini ${ }^{1}$, and Jeffrey B. Birch ${ }^{2}$ \\ Virginia Polytechnic Institute and State University, Blacksburg, VA 24061
}

Additional index words. Malus domestics, net photosynthesis, stomatal conductance, water-use efficiency, specific leaf weight, dark respiration

\begin{abstract}
Light response curves for gas exchange characteristics were developed for spur leaves of 'Stayman' and 'Delicious' apple (Malus domestica Borkh.) from interior, intermediate, and exterior canopy positions throughout the season. At full bloom (FB), before full leaf expansion, exterior leaves had higher maximum rates of net photosynthesis (Pn), and a statistically different Pn light response curve than the interior leaves. Intermediate leaves had intermediate Pn rates and light response curves. Pn light response curves for all three 'Delicious' canopy positions differed from each other from FB + 6 weeks until the end of the season. Interior leaves had maximum Pn rates of only $50 \%$ to $60 \%$ of those for the exterior leaves from $\mathrm{FB}+10$ weeks until the end of the season. Light saturation levels were higher for the exterior leaves than for interior or intermediate leaves. Exterior leaves had a tendency throughout the season for higher quantum efficiency of Pn at subsaturating light levels than interior or intermediate leaves. Stomatal conductance was higher for the exterior than the interior or intermediate leaves of 'Delicious' on all dates. Water-use efficiency was equivalent among all leaves. Exterior leaves had higher specific leaf weight, dark respiration rates, and incident light levels on all dates than interior or intermediate leaves.
\end{abstract}

Light environment influences leaf anatomy, morphology, and physiology among a wide range of plant species (Bazzaz and Carlson, 1982; Fails et al., 1982a, 1982b; Mahall and Schlesinger, 1982; Syvertsen, 1984). Consequently, natural shading within a plant canopy results in anatomically distinct leaves with differing gas exchange characteristics (Nobel, 1976; Schaffer and Gaye, 1989). Previous studies with apple have focused primarily on the influence of the light environment on maximum photosynthetic rates either under light-saturated conditions (Barden, 1974, 1977; Porpiglia and Barden, 1980), or ambient light conditions (Heinicke, 1966). However, because light levels within the major part of an apple canopy are below light saturation (Heinicke, 1963; Porpiglia and Barden, 1980), gas exchange responses to differing light levels (light response curves) are of interest. Also, there is little information available on how light response curves for gas exchange characteristics change during the season for leaves at various canopy positions. Such information could influence pruning practices and could be useful for modelling whole-canopy gas exchange characteristics. The objective of this study was to develop light response curves for the gas exchange characteristics of apple spur leaves from interior, intermediate, and exterior canopy positions throughout the growing season.

\section{Materials and Methods}

Five 23-year-old 'Stayman'/MM.11l were used in 1989, and four 15-year-old 'Red Prince Delicious'/MM. 111 were used in 1990. All trees were located on the Virginia Polytechnic Institute and State Univ. Horticulture Farm, Blacksburg. 'Stayman' trees had an average height and width of 6.1 and $5.1 \mathrm{~m}$, respectively, and an average trunk circumference of $79 \mathrm{~cm}$. Rows were" oriented north-south with a 6. 1-m in-row and 6. 1-m be-

Received for publication 22 Jan. 1992. Accepted for publication 4 Feb. 1992. The cost of publishing this paper was defrayed in part by the payment of page charges. Under postal regulations, this paper therefore must be hereby marked advertisement solely to indicate this fact.

'Dept. of Horticulture.

${ }^{2}$ Dept. of Statistics. tween-row spacing. 'Delicious' trees had an average height and width of 5.4 and $4.8 \mathrm{~m}$, respectively, and a trunk circumference of $60 \mathrm{~cm}$. Rows were oriented east-west with a $5.5-\mathrm{m}$ in-row and a $6.1-\mathrm{m}$ between-row spacing. At budbreak, four nonfruiting spurs in 1989 and eight nonfruiting spurs in 1990 were tagged at each of the interior, intermediate, and exterior canopy positions of each tree; one spur was randomly selected at each position per tree per measurement date. Exterior spurs were selected on 2nd-year wood as near to the periphery of the canopy as possible, intermediate spurs were selected $\approx 40$ to $60 \mathrm{~cm}$ toward the trunk from the exterior position, and interior spurs were selected within $30 \mathrm{~cm}$ of the trunk. All spurs were selected on the west side of the 'Stayman' trees and the south side of the 'Delicious' trees and were chosen for uniformity of bud diameter and stage of development.

Light response curves were developed for 'Stayman' in 1989 on four dates: FB, and FB $+2,4$, and 18 weeks; and for 'Delicious' in 1990 on eight dates: $\mathrm{FB}$, and FB $+2,4,6,10$, 14,18 , and 22 weeks. Gas exchange characteristics were measured on one primary leaf per spur per canopy position per tree. On the day before measurement, spurs were detached from the trees between 1800 and $2000 \mathrm{HR}$ and the cut ends were placed in water overnight in the laboratory (Barden et al., 1980). Pn was measured in an open system with an Anarad model AR600 infrared gas analyzer (Anarad, Santa Barbara, Calif.). The leaf chamber was a modification of the one described by Syvertsen and Smith (1983) but without a heat exchanger. Fans were used to negate boundary layer resistance. Air flow through the chamber was maintained at 0.033 or 0.05 liter $\cdot \mathrm{s}^{-1}$, depending on leaf area. Air within the chamber was maintained at 28 $\pm 3 \mathrm{C}$. Lighting was provided by $500 \mathrm{R} / 3 \mathrm{FL}$ metal halide lamps (Westinghouse), and light levels were altered by covering the chambers with layers of neutral screening. Light levels of $\approx 0$, $35,150,350,500,750$, and $1150 \mu \mathrm{mol} \cdot \mathrm{m}^{-2} \cdot \mathrm{s}^{-1}$ were used. Shading treatments were applied from least to most shade without randomization, as a preliminary experiment yielded equal

Abbreviations: FB, full bloom; Pn, net photosynthesis; PPFD, photosynthetic photon flux density. 
results for randomized and nonrandomized shading treatments. PPFD was measured at each shade level in the laboratory with a quantum sensor at the level of the leaf in the chamber. Following Pn measurements in the light, dark respiration was measured by turning off the lights and covering the chambers for 15 min. Carbon dioxide exchange was the only gas exchange characteristic measured for 'Stayman' leaves.

For 'Delicious' leaves, dew point of the air in the chamber was measured, simultaneously with Pn, with a General Eastern model 1100 dew point hygrometer (General Eastern Instruments, Watertown, Mass.). These measurements were used to calculate stomatal conductance $\left(\mathrm{g}_{\mathrm{s}}\right)$ according to Moon and Flore (1986). Intercellular $\mathrm{CO}_{2}$ concentrations could not be calculated because absolute concentration of $\mathrm{CO}_{2}$ in the chamber was not recorded. Water-use efficiency (WUE) was calculated by dividing Pn by transpiration (from dew point measurements). Following gas exchange measurements, the leaves were removed and area was measured with a LI-3000 leaf area meter (LI-COR, Lincoln, Neb.). Leaves were dried at 60C for 3 days, weighed, and specific leaf weight (SLW) calculated. Photosynthetic photon flux density was measured at each spur position within the 'Delicious' canopy with a LI-COR quantum sensor (Model LI185 ) on the first overcast day following gas exchange measurements and expressed as a percentage of incident PPFD (\%IPPFD).

Light response curves for Pn were fit to the data by twoparameter nonlinear regression analysis using the PROC NLIN procedure in SAS (SAS, 1985). These regression models are based on MacArthur-Wilson equilibrium equations developed to model zoological colonization on noninteractive islands (MacArthur and Wilson, 1963) given here as:

$$
\mathrm{Pn}=\mathrm{S}_{\mathrm{Pn}} *\left(1-\mathrm{e}^{-\mathrm{G} * \mathrm{PPFD}}\right)
$$

where $S_{\mathrm{Pn}_{n}}$ is the maximum $\mathrm{Pn}$ rate, and $\mathrm{G}$ is the rate of approach to maximum. Light response curves for $\mathrm{g}_{\mathrm{s}}$ were fit to the data using three-parameter nonlinear regression because $g_{s}$ data did not approach 0 at 0 PPFD, making the two-parameter nonlinear model statistically inferior for these data. The three-parameter equation is:

$$
\mathrm{g}_{\mathrm{s}}=\mathrm{S}_{\mathrm{gs}}-\left(\mathrm{Y} * \mathrm{e}^{-\mathrm{G}^{*}}{ }^{\mathrm{PPFD}}\right)
$$

where $S_{g s}$ is the maximum $g_{s}$ rate, $G$ is the rate of approach to maximum, and $\mathrm{Y}$ is the $\mathrm{S}_{\mathrm{ss}}-$ (y-axis intercept). Indicator (dummy) variables were used to test all pairwise comparisons of regression models per date per year (Montgomery and Peck, 1982). Experimentwise error rates were held constant at $\alpha=$ 0.05 by adjusting the alpha level for each comparison $(\mathrm{a} /$ number of pairwise comparisons). Pseudo $R^{2}$ were used to assess goodness of fit and were determined for each model by dividing the regression sums of squares by the total uncorrected sums of squares. PPFD levels for 95\% saturation of Pn (light saturation point) were calculated for each position and date using the two equations above, but were not statistically compared.

\section{Results}

Differences in the Pn light response curves occurred at FB for spur leaves from the three 'Stayman' canopy positions (Table 1). The exterior leaves had higher $S_{\mathrm{Pn}}$ than the interior leaves; intermediate leaves had an intermediate $\mathrm{S}_{\mathrm{Pn}}$. On the remaining dates, $\mathrm{FB}+2,4$, and 18 weeks, the exterior leaves had a higher $S_{\mathrm{pn}}$ and rate of approach to maximum (indicated by a lower $\mathrm{G}$ ), and the interior and intermediate leaves had equivalent saturation curves. Similar results were found for 'Delicious'
Table 1. Regression coefficients for net photosynthetic $\left(\mu \mathrm{mol} \cdot \mathrm{m}^{-2} \cdot \mathrm{s}^{-1}\right)$ light response curves and light saturation levels of 'Stayman' leaves from interior, intermediate, and exterior canopy positions at four

\begin{tabular}{|c|c|c|c|}
\hline \multirow{2}{*}{$\begin{array}{l}\text { Canopy } \\
\text { position }\end{array}$} & \multicolumn{2}{|c|}{$\begin{array}{l}\text { Photosynthetic } \\
\text { regression coefficients }\end{array}$} & \multirow{2}{*}{$\begin{array}{c}\text { Light } \\
\text { saturation } \\
\text { levely }\end{array}$} \\
\hline & $S_{P_{n}}$ & $\mathrm{G}$ & \\
\hline \multicolumn{4}{|c|}{$F B$} \\
\hline Interior & $4.5 \mathrm{a}$ & $0.0042 \mathrm{a}$ & 713 \\
\hline Intermediate & $6.5 \mathrm{ab}$ & $0.0040 \mathrm{a}$ & 748 \\
\hline Exterior & $7.8 \mathrm{~b}$ & $0.0033 \mathrm{a}$ & 908 \\
\hline \multicolumn{4}{|c|}{$F B+2$ weeks } \\
\hline Interior & $14.2 \mathrm{a}$ & $0.0040 \mathrm{~b}$ & 748 \\
\hline Intermediate & $16.2 \mathrm{a}$ & $0.0039 \mathrm{~b}$ & 768 \\
\hline Exterior & $21.7 \mathrm{~b}$ & $0.0032 \mathrm{a}$ & 936 \\
\hline \multicolumn{4}{|c|}{$F B+4$ weeks } \\
\hline Interior & $15.5 \mathrm{a}$ & $0.0064 \mathrm{~b}$ & 468 \\
\hline Intermediate & $15.5 \mathrm{a}$ & $0.0056 \mathrm{~b}$ & 534 \\
\hline Exterior & $18.3 \mathrm{~b}$ & $0.0037 \mathrm{a}$ & 810 \\
\hline \multicolumn{4}{|c|}{$F B+18$ weeks } \\
\hline Interior & $8.6 \mathrm{a}$ & $0.0073 \mathrm{~b}$ & 410 \\
\hline Intermediate & $9.6 \mathrm{a}$ & $0.0061 \mathrm{~b}$ & 491 \\
\hline Exterior & $13.0 \mathrm{~b}$ & $0.0040 \mathrm{a}$ & 748 \\
\hline
\end{tabular}
sampling dates. ${ }^{2}$ Equation: $\mathrm{Pn}=\mathrm{S}_{\mathrm{Pn}} *\left[1-\mathrm{e}^{\text {(-G.PPFD) }}\right]$.

${ }^{2}$ Coefficients within columns and dates followed by the same letter do not differ at an experimentwise error rate of $0.05(n=5)$. Coefficients were compared with indicator variables.

${ }^{y}$ PPFD level $\left(\mu \mathrm{mol} \cdot \mathrm{m}^{-2} \cdot \mathrm{s}^{-1}\right.$, where Pn was $95 \%$ of maximum.

in 1990, but the increased frequency of measurement better illustrated seasonal trends. Again, at FB there were differences in the Pn light response curves of spur leaves from the three canopy positions (Table 2, Fig. 1). The exterior leaves had a higher $S_{\mathrm{pn}}$ and lower $\mathrm{G}$ than the interior leaves. The intermediate leaves had intermediate $S_{\mathrm{Pn}}$. and $\mathrm{G}$ values. By $\mathrm{FB}+2$ and $\mathrm{FB}$ +4 weeks, the interior and intermediate leaves had smaller $S_{\mathrm{Pn}}$ values than the exterior leaves, and interior and exterior leaves still differed in $\mathrm{G}$. By FB +6 weeks and for the remainder of the season $(\mathrm{FB}+10,14,18,22$ weeks) leaves from all three positions differed in $\mathrm{S}_{\mathrm{pn}}$. Interior and exterior leaves also had different $G$ values, but $G$ values were similar for the interior and intermediate leaves. Pseudo $R^{2}$ were $\geq 0.95$ for all regression curves, demonstrating the excellent goodness of fit for the models to the data (Fig. 1).

Light saturation points for Pn were higher for the exterior leaves of both 'Stayman' and 'Delicious' on all dates (Tables 1 and 2; Fig. 1 for 'Delicious'). The lowest light saturation points for leaves at all positions were reached by $\mathrm{FB}+14$ or $\mathrm{FB}+$ 18 weeks with 'Delicious'. Exterior leaves appeared to have higher quantum efficiency at sub-saturating PPFD levels than leaves at the other positions (Fig. 1), but no statistical differences were found when linear equations were fit to the Pn data at PPFD levels $<200 \mu \mathrm{mol} \cdot \mathrm{m}^{-2} \cdot \mathrm{s}^{-1}$ for each position and compared with indicator variables.

Exterior leaves had higher maximum $g_{s}$ values $\left(S_{g s}\right)$ than interior leaves at $\mathrm{FB}+0,2$, and 4 weeks, and intermediate leaves had intermediate $S_{\mathrm{gs}}$ values (Table 2, Fig. 2). There was no difference in $G$ or $Y$ among the positions on these dates. By $\mathrm{FB}+6$ weeks, and for the remainder of the season, intermediate and exterior leaves had higher $S_{g s}$ values than interior leaves, and $\mathrm{G}$ and $\mathrm{Y}$ remained equal among all three positions. Pseudo $R^{2}$ were $\geq 0.93$ for the regression curves for all dates 
Table 2. Regression coefficients for light response curves of net photosynthesis $\left(\mu \mathrm{mol} \cdot \mathrm{m}^{-2} \cdot \mathrm{s}^{-1}\right)$ and stomatal conductance $\left(\mathrm{mmol} \cdot \mathrm{m}^{-2} \cdot \mathrm{s}^{-1}\right)$, and light saturation levels of 'Delicious' leaves from interior, intermediate, and exterior canopy positions on eight sampling dates.' Equations: $\mathrm{Pn}=\mathrm{S}_{\mathrm{Pn}} *\left[1-\mathrm{et}^{\text {(G.PPD) }}\right] ; \mathrm{g}_{\mathrm{s}}=\mathrm{S}_{\mathrm{GS}}-\left[\mathrm{Y}-\mathrm{e}\left(^{-\mathrm{G}}\right.\right.$ PPFD)].

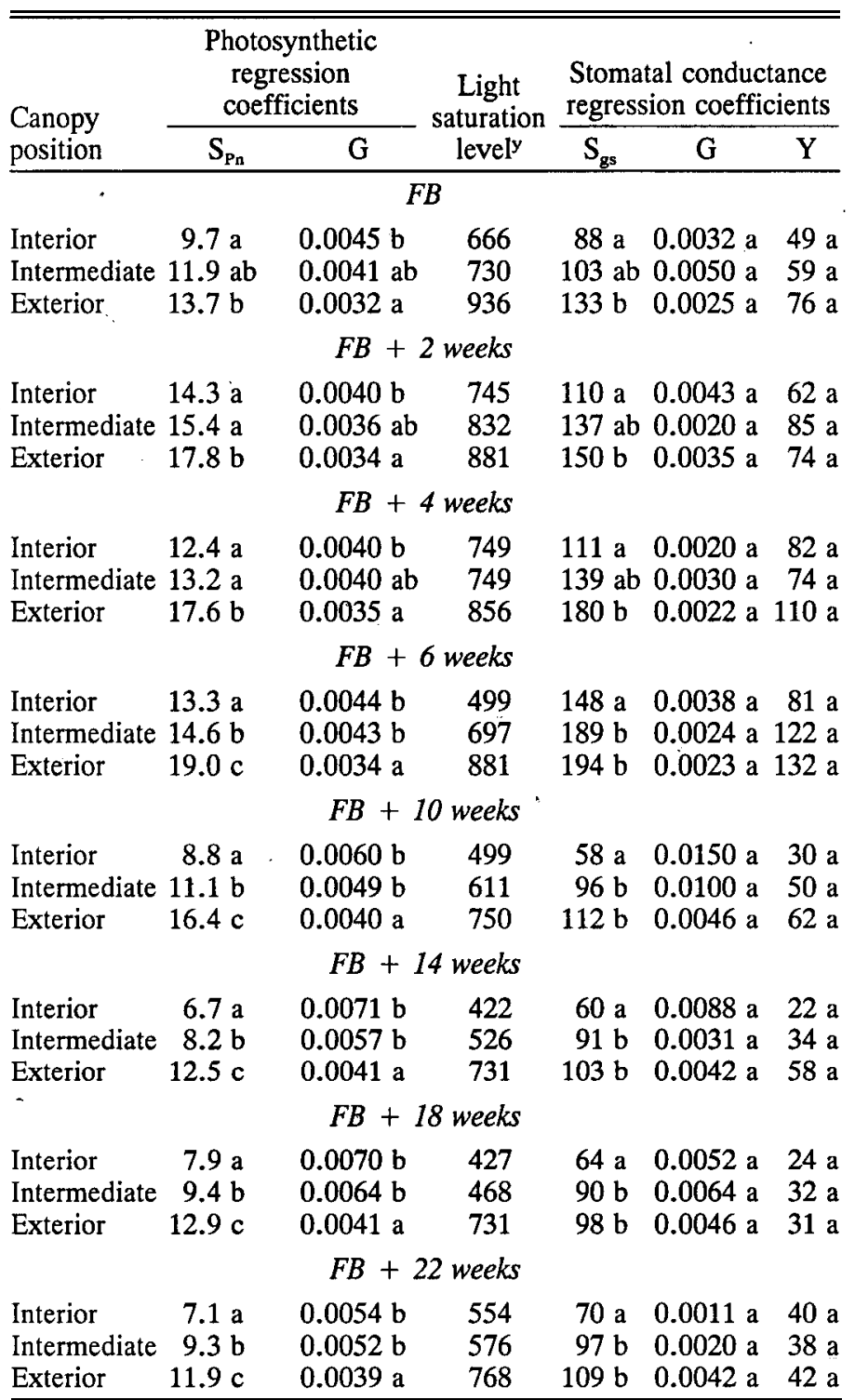

${ }^{2}$ Coefficients within columns and dates followed by the same letter do not differ at an experimentwise error rate of $0.05(n=4)$. Coefficients were compared with indicator variables.

${ }^{y}$ PPFD level $\left(\mu \mathrm{mol} \cdot \mathrm{m}^{-2} \cdot \mathrm{s}^{-1}\right)$ where Pn was $95 \%$ of maximum.

and positions. Maximum WUE ranged from 3.2 to $5.7 \mu \mathrm{mol}$ $\mathrm{CO}_{2} / \mathrm{mmol} \mathrm{H}_{2} \mathrm{O}$ during the season and was equivalent among the three canopy positions on all dates. There was no apparent increasing or decreasing trend in WUE throughout the season (data not presented).

Percent IPPFD measured next to the spurs was highest at the exterior position on all dates (Table 3). The interior and intermediate positions did not statistically differ, although there was a trend for higher \%IPPFD at the intermediate position on all dates. Percent IPPFD decreased to a minimum by about FB + 6 weeks, and remained similar for the remainder of the season. Statistical differences in SLW were evident by FB +2 weeks and for the remainder of the season (Table 3). Exterior leaves

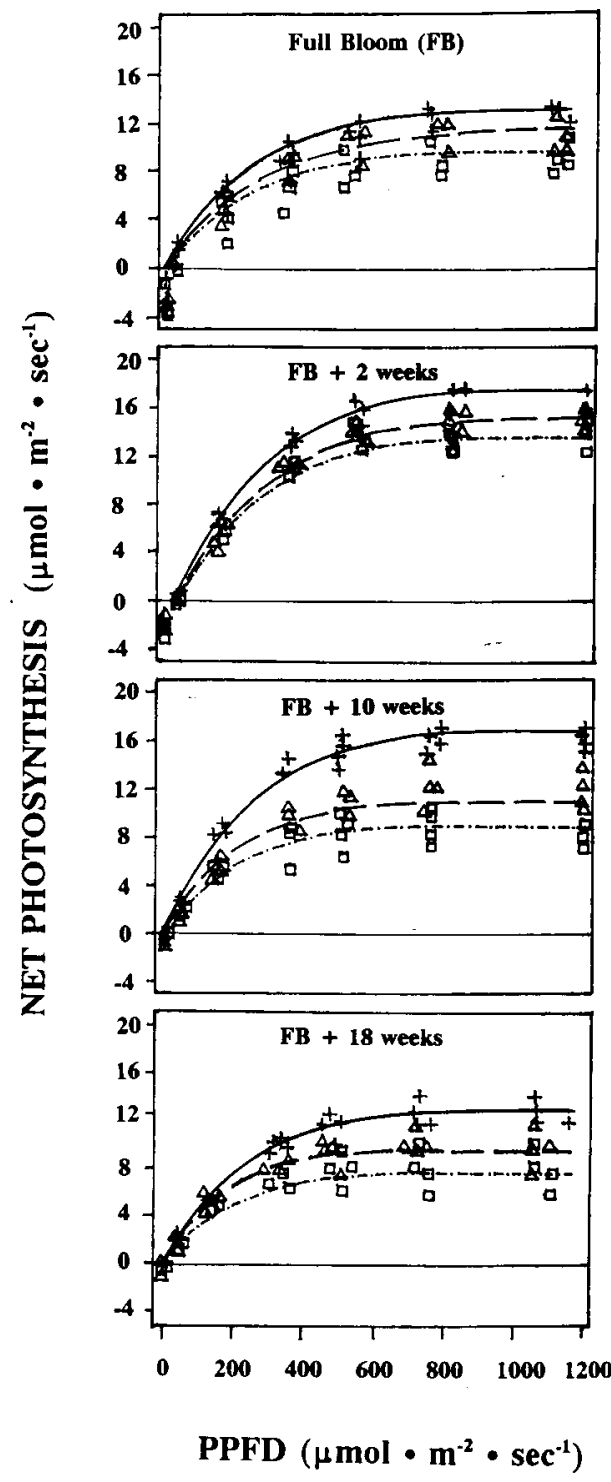

Fig. 1. Light response curves of 'Delicious' spur leaves for net photosynthesis measured at FB, FB +2 weeks, FB +10 weeks, and $\mathrm{FB}+18$ weeks. MacArthur-Wilson saturation equations represent the interior $(\square,-\cdots-)$, intermediate $(\triangle,--)$, and exterior $(+$, $\longrightarrow$ ) canopy positions. Equations (interior, intermediate, exterior): $\mathrm{FB} ; \mathrm{Pn}=9.7 *\left[1-\mathrm{e}^{\left(-0.0045^{* P P F D}\right)}\right], \mathrm{Pn}=11.9 *$ $\left[1-\mathrm{e}^{\left(-0.0041^{* P P F D}\right)}\right], \mathrm{Pn}=13.7 *\left[1-\mathrm{e}^{\left(-0.0032^{*} \text { PPFD }\right)}\right] \cdot \mathrm{FB}+2$ weeks; $\mathrm{Pn}=14.3 *\left[1-\mathrm{e}^{\left(-0.0040^{*} \mathrm{PPFD}\right)}\right], \mathrm{Pn}=15.4 *$ $\left[1-\mathrm{e}^{\left(-0.0036^{*} \mathrm{PPF}\right)}\right], \mathrm{Pn}=17.8 *\left[1-\mathrm{e}^{\left(-0.0034^{*} \mathrm{PPFD}\right)}\right] . \mathrm{FB}+10$ weeks; $\mathrm{Pn}=8.8 *\left[1-\mathrm{e}^{\left(-0.0060^{*} \mathrm{PPFD}\right)}\right], \mathrm{Pn}=11.1 *$ $\left[1-\mathrm{e}^{\left(-0.0049^{*} \mathrm{PPFD}\right)}\right], \mathrm{Pn}=16.4 *\left[1-\mathrm{e}^{\left(-0.0040^{*} \mathrm{PPFD}\right)}\right] . \mathrm{FB}+18$ weeks; $\mathrm{Pn}=7.9 *\left[1-\mathrm{e}^{\left(-0.0070^{*} \text { PPFD }\right)}\right], \mathrm{Pn}=9.4 *$ $\left[1-\mathrm{e}^{\left(-0.0064^{*} \mathrm{PPFD}\right)}\right], \mathrm{Pn}=12.9 *\left[1-\mathrm{e}^{\left(-0.0041^{*} \mathrm{PPFD}\right)}\right]$.

had higher SLW, and interior and intermediate leaves were statistically equivalent, although there was a trend for higher SLW at the intermediate position. SLW increased throughout the season for all of the positions. Dark respiration (Rd) was highest for the exterior leaves on all dates. After FB +2 weeks, Rd tended to decrease for all three positions until $\mathrm{FB}+18$ weeks.

\section{Discussion}

Reductions in maximum Pn of 50\% were reported for leaves of many species grown in low-light environments relative to those in full sun (Bazzaz and Carlson, 1982; Kappel and Flore, 


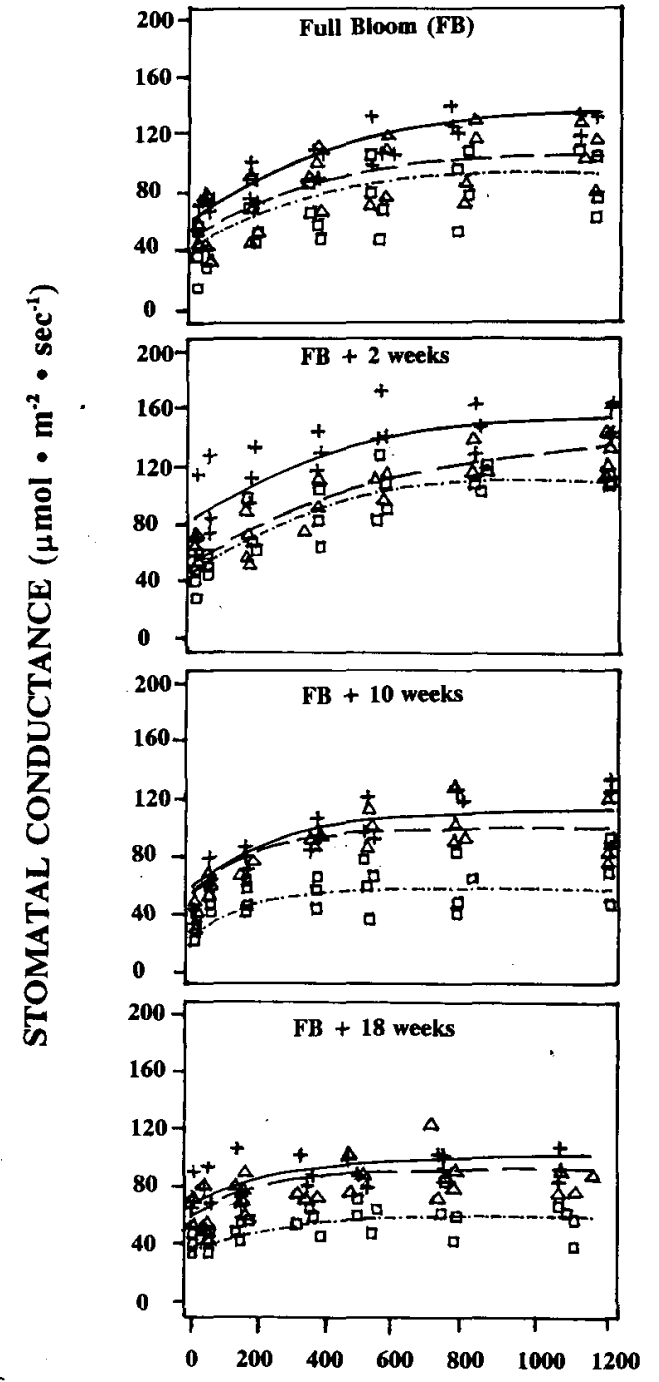

Fig. 2. Light response curves of 'Delicious' spur leaves for stomatal conductance $\left(\mathrm{g}_{\mathrm{s}}\right)$ measured at $\mathrm{FB}, \mathrm{FB}+2$ weeks, FB +10 weeks, and $\mathrm{FB}+18$ weeks. McArthur-Wilson equilibrium equations represent the interior $(\square, \cdots-\cdot)$, intermediate $(\triangle, \cdots)$, and exterior $(+,-)$ canopy positions. Equations (interior, intermediate, exterior): $\mathrm{FB} ; \mathrm{g}_{\mathrm{s}}=88-\left[49-\mathrm{e}^{\left(-0.0032^{* P P F D}\right)}\right], \mathrm{g}_{\mathrm{s}}=103-[59-$ $\left.\mathrm{e}^{\left(-0.0050^{*} \text { PPFD }\right)}\right], \mathrm{g}_{\mathrm{s}}=133-\left[76-\mathrm{e}^{\left(-0.0025^{*} \mathrm{PPFD}\right)}\right] . \mathrm{FB}+2$ weeks; $\mathrm{g}_{\mathrm{s}}=110-\left[62-\mathrm{e}^{\left(-0.0043^{*} \text { PPFD }\right)}\right], \mathrm{g}_{\mathrm{s}}=137-[85-$

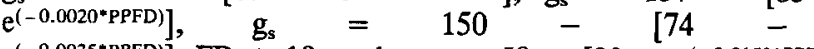
$\left.\mathrm{e}^{\left(-0.0035^{*} \mathrm{PPFD}\right)}\right] . \mathrm{FB}+10$ weeks; $\mathrm{g}_{\mathrm{s}}=58-\left[30-\mathrm{e}^{\left(-0.0150^{*} \mathrm{PPFD}\right)}\right]$, $\mathrm{g}_{\mathrm{s}}=96-\left[50-\mathrm{e}^{\left(-0.0100^{*} \mathrm{PPFD}\right)}\right], \mathrm{g}_{\mathrm{s}}=112-[62-$
$\left.\mathrm{e}^{\left(-0.0046^{*} \mathrm{PPFD}\right)}\right] . \mathrm{FB}+18$ weeks; $\mathrm{g}_{\mathrm{s}}=64-\left[24-\mathrm{e}^{\left(-0.0052^{*} \text { PPFD }\right)}\right]$, $\mathrm{g}_{\mathrm{s}}=90-\left[32-\mathrm{e}^{\left(-0.0064^{*} \mathrm{PPFD}\right)}\right], \mathrm{g}_{\mathrm{s}}=98-[31-$ $\left.\mathrm{e}^{\left(-0.0046^{*} \mathrm{PPFD}\right)}\right]$.

1983; Nobel, 1976). Barden $(1974,1977)$ reported that maximum Pn (measured at saturating light levels) of apple leaves grown in an artificially imposed low-light environment of $20 \%$ of full sun was $70 \%$ of that for leaves from a high-light environment. Under natural shade conditions within an apple canopy, interior leaves had only $70 \%$ of the maximum Pn rate of the exterior leaves (Heinicke, 1966). Porpiglia and Barden (1980) measured maximum Pn of spur leaves from different positions within 'Stayman' apple canopies throughout the season. At saturating light levels maximum $\mathrm{Pn}$ of interior leaves was $\approx 75 \%$
Table 3. Percent incident PPFD (\%IPPFD), specific leaf weight (SLW), and dark respiration (Rd) of 'Delicious' leaves from interior, intermediate, and exterior canopy positions.'

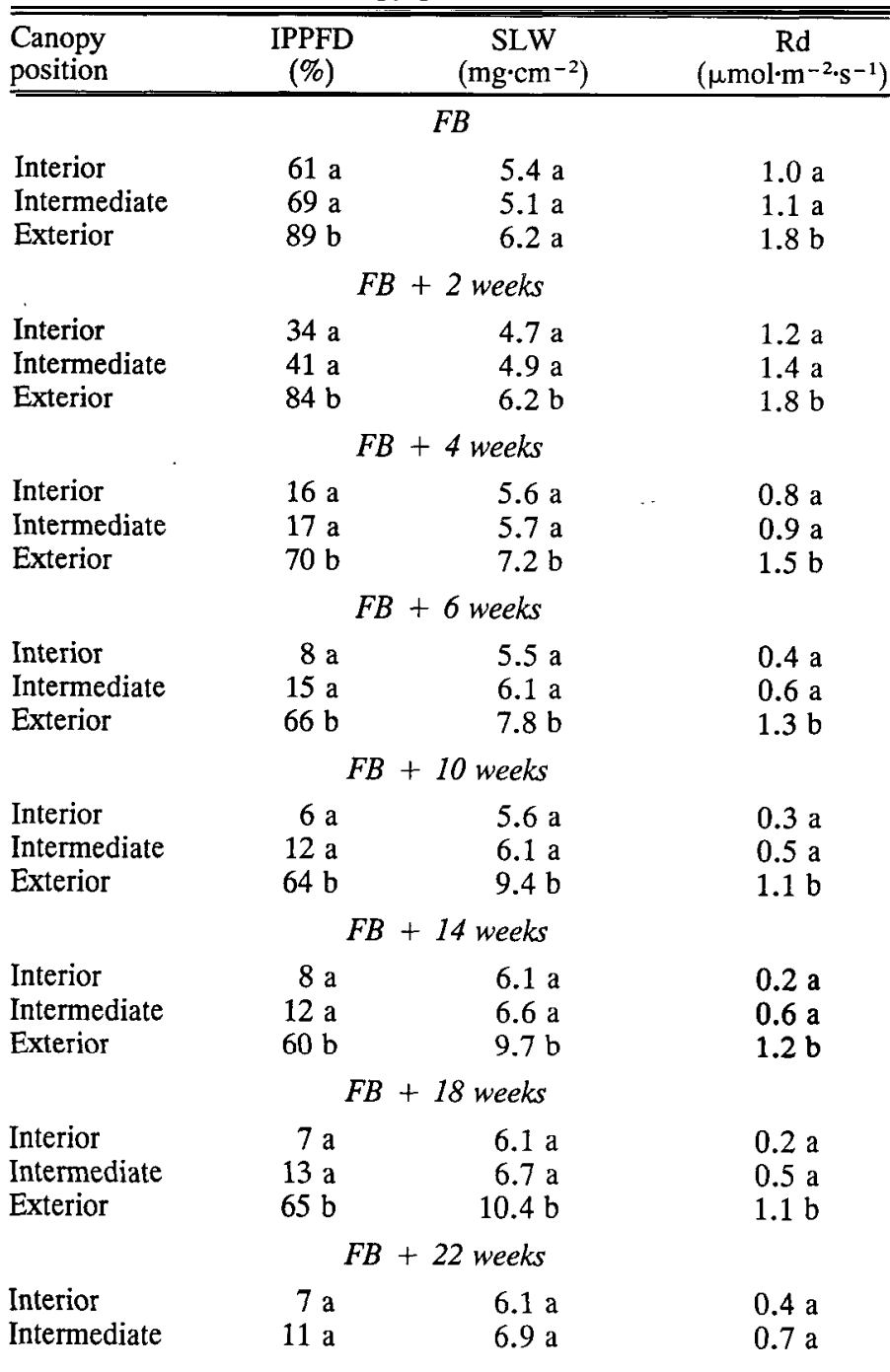

${ }^{2}$ Means within columns and dates followed by the same letter do not differ at $P=0.05$, by Tukey's HSD $(\mathrm{n}=4)$.

of that for exterior leaves through 8 weeks after FB; similar reductions in maximum Pn of interior leaves were found for 'Stayman' and 'Delicious' in our study. Measurements made by Porpiglia and Barden (1980) at 14 and 20 weeks after FB demonstrated a marked decline in Pn of the interior leaves, while Pn of the exterior leaves declined only slightly, resulting in interior leaves with 55\% to $60 \%$ of the Pn rate of exterior leaves. Our data had the same trend, and by FB +10 weeks, until the end of the season, the maximum Pn of the interior leaves was $50 \%$ to $60 \%$ of that for the exterior leaves.

In addition to maximum Pn, light response curves for Pn differed for low- and high-light leaves of apple (Barden, 1977), Ficus benjamina L. (Fails et al., 1982b), and peach [Prunus persica (L.) Batsch.] (Kappel and Flore, 1983). Within mature citrus (Syvertsen, 1984) and mango (Mangifera indica L.) (Schaffer and Gaye, 1989) canopies there were differences in Pn light response curves between interior and exterior leaves. Our Pn light response curves for the different canopy positions agree with these previous studies. Although maximum $\operatorname{Pn}\left(\mathrm{S}_{\mathrm{p}}\right)$ and rates of approach to maximum Pn $(\mathrm{G})$ changed over the 
season, the relationship among the positions was similar throughout the season. In general, 'Stayman' and 'Delicious' had similar responses throughout the season; however, the interior and intermediate 'Stayman' leaves had coincident light response curves after FB +2 weeks, while light response curves differed for these positions within the 'Delicious' canopy. This difference may have been due to increased shading within the 'Stayman' trees because they were larger, although light levels were not measured to confirm this. This similarity in response of interior and intermediate leaves also indicates that the transitional zone between interior and exterior leaves (intermediate position) is relatively narrow and close to the periphery of the canopy.

Use of indicator variables with MacArthur-Wilson equilibrium equations was advantageous because it allowed statistical comparison of the entire light response curve, and we were therefore able to determine whether two light response curves differed from each other. Previous researchers with tree fruits often fitted the data by eye with no statistical comparison, or separations were made at discrete points along the response curve (Barden, 1977; Syvertsen, 1984). Such methods yield no information about the rate of approach to maximum $(G)$. For example, if the maximum Pn rates $\left(S_{\mathrm{P}_{n}}\right)$ were equivalent for two sets of leaves, $\mathrm{G}$ could be used as an indicator of quantum efficiency. McArthur-Wilson equilibrium equations have more biological relevance than quadratic equations because they lack the decrease in response at higher light levels found with quadratic equations. MacArthur-Wilson equations have the disadvantage of not fitting the $\mathrm{Rd}$ portion of the curve due to the limitations of the exponential equation, so light compensation points cannot be directly determined with these equations.

Enhanced quantum efficiency at subsaturating light levels was reported for leaves from low-light environments with citrus (Syvertsen, 1984), F. benjamina (Fails et al., 1982b), peach (Kappel and Flore, 1983), and Fragaria vesca L. (Chabot and Chabot, 1977) although data were statistically analyzed only for citrus. In contrast, Fig. 1 demonstrates that on any date in our study, the exterior leaves had an equal or possibly higher quantum efficiency (nonsignificant trend) than the intermediate or interior leaves at all PPFD levels. In agreement with our results, Schaffer and Gaye (1989) reported that mango leaves in high light had higher quantum efficiency at subsaturating light levels than leaves in low light; no statistical difference in quantum efficiency was reported for other plant species from low- and highlight environments (Bjorkman and Holmgren, 1963; Mahall and Schlesinger, 1982). Some of the reported differences in quantum efficiency are probably due to the lack of statistical comparison, but it may also differ with plant species considered, as Bazzaz and Carlson (1982) reported considerable variation in the relationship among plant species between leaves from lowand high-light environment.

Anatomical differences in leaves due to light environment probably contributed in part to the reductions in Pn potential of interior and intermediate leaves, as evidenced by the suppression of SLW at these positions. Previous studies with many plant species demonstrated that leaves grown in a low-light environment were thinner and larger, with lower SLW and a thinner, poorly developed palisade layer, while leaves from a highlight environment were thicker and smaller, with higher SLW and a thicker, well-developed palisade layer (Chabot and Chabot, 1977; Fails et al. 1982a; Jackson and Palmer, 1977; Mahall and Schlesinger, 1982; Wooge and Barden, 1987). Seasonal trends and values of SLW were similar to those previously re- ported for apple (Marini and Barden, 1981; Porpiglia and Barden, 1980). Marini and Barden (1981) reported that SLW was correlated with Pn potential throughout the season $\left(R^{2} \geq 0.49\right)$, with the poorest relationships early and late in the season. $\mathrm{Rd}$ rates and trends throughout the season were similar to those previously reported for apple (Marini and Barden, 1981; Porpiglia and Barden, 1980).

Reductions in Pn potential could be due in part to a stomatal limitation to $\mathrm{CO}_{2}$ diffusion $\left(\mathrm{g}_{\mathrm{s}}\right)$, because the interior position had $g_{s}$ rates only $50 \%$ to $70 \%$ of that for the exterior position. Reduced leaf conductance to water was reported for $F$. benjamina (Fails et al., 1982b) and chapparal shrub (Ceanothus megaearpus Nutt.) (Mahall et al., 1981) leaves grown in low-light environments, and Schaffer and Gaye (1989) reported reduced $\mathrm{g}_{\mathrm{s}}$ for interior canopy leaves of mango. The reduced $\mathrm{g}_{\mathrm{s}}$ of the interior leaves may be due to a suppression of stomatal density of these leaves, as previously reported in F. benjamina (Fails et al., 1982a), and Sinapis alba (Wild and Wolf, 1980). Mahall and Schlesinger (1982) reported that WUE was higher for chaparral shrub leaves from a high-light environment, and this was also reported for citrus leaves (Syvertsen, 1984). However, in agreement with our results, no effect of light environment on WUE was reported for mango leaves (Schaffer and Gaye, 1989).

Unless leaves at interior positions were predisposed to an inferior gas exchange capacity due to the previous season's light environment, the reduction in available light from $89 \%$ to $61 \%$ IPPFD at FB, although relatively small, had a significant influence on gas exchange capacity of the leaves. We are unaware of other studies measuring Pn potential of spur leaves this early in the season for comparative purposes. The influence of the previous season's light environment on early season Pn potential deserves further study, and the results may lead to changes in canopy management practices. The apple canopy late in the season has been described as possessing two distinct zones of Pn potential: a thin exterior canopy with higher maximum Pn potential and an interior canopy with a lesser maximum Pn potential (Heinicke, 1966). Our results indicate that the exterior canopy leaves also possess statistically different $\mathrm{Pn}$ and $\mathrm{g}_{\mathrm{s}}$ light response curves throughout the season. For precise whole-canopy modelling and cultural techniques designed to manage the physiology of the canopy as related to light, these gas exchange characteristics of the leaves should be considered.

\section{Literature Cited}

Barden, J.A. 1974. Net photosynthesis, dark respiration, specific leaf weight, and growth of young apple trees as influenced by light regime. J. Amer. Soc. Hort. Sci. 99:547-551.

Barden, J.A. 1977. Apple tree growth, net photosynthesis, dark respiration, and specific leaf weight as affected by continuous and intermittent shade. J. Amer. Soc. Hort. Sci. 102:391-394.

Barden, J.A., J.M. Love, P.J. Porpiglia, R.P. Marini, and J.D. Caldwell. 1980. Net photosynthesis and dark respiration of apple leaves are not affected by shoot detachment. HortScience 15:595-597.

Bazzaz, F.A. and R.W. Carlson. 1982. Photosynthetic acclimation to variability in the light environment of early and late successional plants. Oecologia 54:313-316.

Bjorkman, O. and P. Holmgren. 1963. Adaptability of the photosynthetic apparatus to light intensity in ecotypes from exposed and shaded habitats. Physiol. Plant. 16:889-914.

Chabot, B.F. and J.F. Chabot. 1977. Effects of light and temperature on leaf anatomy and photosynthesis in Fragaria vesca. Oecologia 26:363-377.

Fails, B. S., A.J. Lewis, and J.A. Barden. 1982a. Anatomy and morphology of sun- and shade-grown Fics benjamina. J. Amer. Soc Hort. Sci. 107:754-757. 
Fails, B. S., A.J. Lewis, and J.A. Barden. 1982b. Net photosynthesis and transpiration of sun- and shade-grown Ficus benjamina leaves. J. Amer. Soc Hort. Sci. 107:758-761.

Heinicke, D.R. 1963. The micro-climate of fruit trees. II. Foliage and light distribution patterns in apple trees. Proc. Amer. Soc. Hort. Sci. 83:1-11.

Heinicke, D.R. 1966. The effect of natural shade on photosynthesis and light intensity in Red Delicious apple trees. Proc. Amer. Soc. Hort. Sci. 88:1-8.

Jackson, J.E. and J.W. Palmer. 1977. Effects of shade on the growth and cropping of apple trees. I. Experimental details and effects on vegetative growth. J. Hort. Sci. 52:245-252.

Kappel, F. and J.A. Flore. 1983. Effect of shade on photosynthesis, specific leaf weight, leaf chlorophyll content, and morphology of young peach trees. J. Amer. Soc. Hort. Sci. 108:541-544.

MacArthur, R.H. and E.O. Wilson. 1963. An equilibrium theory of insular zoogeography. Evolution 17:373-387.

Mahall, B.E. and W.H. Schlesinger. 1982. Effects of irradiance on growth, photosynthesis, and water use efficiency of seedlings of chaparral shrub, Ceanothus metacarpus. Oecologia 54:219-299.

Marini, R.P. and J.A. Barden. 1981. Seasonal correlations of specific leaf weight to net photosynthesis and dark respiration of apple leaves. Photosynthesis Res. 2:251-258.

Montgomery, D.C. and E.A. Peck. 1982. Introduction to linear agression analysis. Wiley, New York.

Moon, J.W. and J.A. Flore. 1986. A BASIC computer program for calculation of photosynthesis, stomatal conductance, and related parameters in an open gas exchange system. Photosynthesis Res. 7:269279.

Nobel, P.K. 1976. Photosynthetic rates of sun versus shade leaves of Hyptis emoryi Torr. Plant Physiol. 58:218-223.

Porpiglia, P.J. and J.A. Barden. 1980. Seasonal trends in net photosynthetic potential, dark respiration, and specific leaf weight of apple leaves as affected by canopy position. J. Amer. Soc. Hort. Sci. 105:920-923.

SAS. 1985. SAS user's guide: Statistics. Version 5 (cd.). SAS Institute, Inc., Cary, N.C.

Schaffer, B. and G.O. Gaye. 1989. Gas exchange, chlorophyll and nitrogen content of mango leaves as influenced by light environment. HortScience 24:507-509.

Syvertsen, J.P. 1984. Light acclimation in citrus leaves. 11. CO, assimilation and light, water, and nitrogen use efficiency. J. Amer. Soc. Hort. Sci. 109:812-817.

Syvertsen, J.P. and M.L. Smith, Jr, 1983. An inexpensive leaf chamber for measuring net gas exchange. HortScience 18:700-701.

Wild, A. and G. Wolf. 1980. The effect of different light intensities on the frequency and size of stomata, the size of cells, the number, size and chlorophyll content of chloroplasts in the mesophyll and guard cells during the ontogeny of primary leaves of Sinapis alba. Z. Pflanzenphysiol. 97:325-342.

Wooge, J.D. and J.A. Barden. 1987. Seasonal changes in specific leaf weight and leaf anatomy of apple. HortScience 22:292-294. 